\title{
EL TEATRO HISPANOAMERICANO EN EL UMBRAL DE LA \\ POSMODERNIDAD 1960-1980
}

\author{
POR \\ Olga Martha Peña Doria \\ GUILleRmo SCHMidHubER DE LA MORA \\ Centro de Estudios Literarios \\ Universidad de Guadalajara, México
}

Este estudio presenta un panorama sucinto de las circunstancias y de los logros que rodearon al teatro hispanoamericano durante los años 1960-1980, dos décadas cruciales que dejaron una huella indeleble en su evolución. Para una mayor comprensión de las aportaciones de este periodo, es imperioso elaborar una periodización de las actividades teatrales de años anteriores $y$, consecuentemente, evaluar el impacto que posteriormente tuvo. Al ensayar una periodización del teatro hispanoamericano en su primera y única centuria teatral, comprobamos la existencia de cinco etapas:

1) La etapa de iniciación 1900-1921, en las dos primeras décadas con la preponderancia de los escenarios de Buenos Aires y la Ciudad de México.

2) La etapa de fundación 1922-1948, en la que descuellan la experimentación(Dauster la califica de "experimentalista," Historia 25) y el interés de formar los primeros grupos estables de teatristas influidos por la vanguardia europea pero con la voluntariedad de propiciar el advenimiento de la dramaturgia nacional, principalmente por la fundación de grupos, como la Comedia Mexicana (1922-1938) y el Teatro de Ulises (1928), ambos en la ciudad de México, y el Teatro del Pueblo (1930), en Argentina. Posteriormente otros países prosiguieron la búsqueda de un teatro hispanoamericano: Cuba, con el Teatro de Arte de la Habana "La Cueva" (1936), y, más tarde, en Puerto Rico, el Grupo Areyto y las labores del Ateneo Puertorriqueño, y en Chile el Teatro Experimental de la Universidad de Chile (1941).

3) La etapa realista con la búsqueda de la temática nacional 1949-1958, con la aparición de una nueva generación de dramaturgos que escribieron obras miméticas en el lenguaje y con personajes de forja hispanoamericana, aunque en muchos casos bajo la influencia del realismo norteamericano (Arthur Miller y Tennessee Williams). ${ }^{1}$

4) La etapa político-social 1959-1986, a partir de la revolución cubana, con la preponderancia de la creación colectiva y de los temas libertarios; en ella se destaca la estética teatral fundamentada en imágenes y la preponderancia del director. Pierde vigencia al disminuir el mare mágnum político.

\footnotetext{
${ }^{1}$ Coincidente con la aparición de una nueva generación de dramaturgos latinoamericanos, fue el estreno de The Death of a Salesman de Miller (1949).
} 
5) La etapa no realista con la simbiosis del teatro de imágenes con el textual, como apunta el inicio de la última década del siglo $\mathrm{XX}$; aunque algunas obras de esta tendencia fueron escritas pioneramente durante las décadas anteriores.

Si comparamos esta periodización con el conteo generacional propuesto por José Juan Arrom en su estudio Esquema generacional de las letras hispanoamericanas (15-24), esta centuria teatral abarca tres generaciones: 1924,1954 y 1984, esta última con predominio hasta 2014. Consecuentemente, las dos décadas que abarca el presente estudio pertenecen a la parte intermedia y final de la generación 1954.

$\mathrm{Al}$ inicio del período abarcado por este análisis se editaron varios estudios que por primera vez analizaron el teatro hispanoamericano per se con una visión continental; sus autores fueron Carlos Solórzano, Agustín del Saz, Willis Knapp Jones y Frank Dauster. ${ }^{2}$ Desde la perspectiva de los años setenta, Dauster afirma el "florecimiento" del teatro por haber "en cada país hispanoamericano un bien desarrollado movimiento teatral de enjundia, con abundancia de estrenos nacionales ... El teatro de agitación política cobra importancia cada vez mayor ... y hay también una tendencia creciente hacia el teatro de tipo ritual y hacia el trabajo de conjunto" (Historia 26). En un esclarecedor estudio de Rosalina Perales escrito a posteriori, describe al teatro de estos años como "fundamentalmente político-social," y agrega:

El realismo reiterado como estilo, la recuperación de un lenguaje más trabajado, la metáfora como carril de significación, el retorno a la alegría y el divertimiento teatral, las obras cortas y el gusto por monólogos y unipersonales, la transformación en el origen de la creación dramática - antes se partía de la idea, ahora, de la imagen (Teatro 50).

Estas dos décadas cambiaron definitivamente la directriz que el teatro llevaba, instituyendo características que a partir de entonces se han considerado definitorias para todo aquello que había de llamarse "teatro latinoamericano."

A pesar de que la tercera etapa se manifestó altamente nacionalista, su influencia extranjera fue mayor que la recibida en las dos etapas anteriores. Las influencias de Piscator y Brecht sirvieron de fundamento estético al teatro expresionista y épico latinoamericano, y más tarde las de Weiss y Hochhuth al teatro testimonial. El teatro de la crueldad de Artaud fue piedra angular para el desarrollo del teatro de imagen y de la posición preponderante del director; esta última tendencia se llevó a cabo especialmente bajo el influjo de Peter Brook, Jerzy Grotowski, Eugenio Barba y Giorgio Strehler. El teatro del absurdo de Beckett y Ionesco dejó honda huella en los estilos dramáticos, especialmente por el uso creciente del género fársico, aunque no tanto en los contenidos de orden filosófico-existencial, que resultaron más afines al espíritu europeo. La importancia de lo social no únicamente se reflejó en los temas, sino que afectó grandemente la concepción del fenómeno teatral, minimizando la importancia del texto, la dramaturgia y el individualismo actoral, para

\footnotetext{
${ }^{2}$ Entre los estudios del teatro hispanoamericano perteneciente a las dos décadas analizadas en el presente artículo, se destacan los de Augusto Boal, Pedro Bravo Elizondo, Mario Cánepa Guzmán, Rine Leal, Matías Montes Huidobro, Rosalina Perales, Grínor Rojo, Beatriz J. Rizk, Carlos Miguel Suárez Radillo, Juan Villegas y George Woodyard. Así como los estudios de Osvaldo Obregón sobre el teatro hispanoamericano en Francia (en prensa).
} 
desarrollar otras formas de trabajo centradas en la escenificación y en la colaboración de los diversos integrantes de la producción teatral. La lucha libertaria pareció encontrar en la dramaturgia una dictadura de apetecible derrocamiento, aunque el vacío de poder generado por la ausencia autoral fue llenado por el papel del director, como lo hacen los vasos comunicantes en la física. El número y la calidad de directores fue grande, se destacaron Atahualpa del Cioppo, Carlos Giménez, Jairo Aníbal Niño, Luis de Tavira, Santiago García, por citar sólo cinco.

Un factor sine qua non de estos años fue que el proceso creativo de escenificación estuvo centrado en los festivales. Cuba fue el iniciador del primer festival latinoamericano en 1961, aunque éste tuvo un balance de producciones mayormente cubano; y sólo en 1964 se llevó a cabo el primer festival con representación de la América hispana continental. Le siguieron varios festivales, como el de Manizales, Colombia, que se inició en 1968, bajo el ejemplo del festival de Nancy, Francia; y el de Caracas, que, aunque fundado en 1959 , alcanzó sus mayores logros en años posteriores. La tiranía de los festivales como jueces de la evolución del teatro latinoamericano puede ser calificada de "festivitis," ya que su criterio fue pontificado y sirvió de paradigma de la especificidad de lo teatral latinoamericano. Por otro lado, estos eventos, que bien pueden calificarse de celebraciones del teatro, por primera vez permitieron la comunicación de los veintiún teatros hispanoamericanos, incluyendo el puertorriqueño y el chicano. Los grupos teatrales fueron sinónimo de lo que debía ser el teatro latinoamericano, como sucedió con el Grupo Escambray (Cuba), el grupo Rajatabla (Venezuela), El Galpón de (Uruguay), Teatro Campesino (EUA), ICTUS y El Aleph (Chile), La Candelaria y el Teatro Experimental de Cali (Colombia), el Yuyachkani y Cuatro Tablas (Perú), y tantos otros; sus éxitos y hasta sus exilios fueron seguidos con ojos observadores desde todos los rincones de nuestra América.

La historia del teatro latinoamericano esconde muchos esfuerzos que no han podido ser incorporados al teatro de las grandes capitales o a los teatros nacionales auspiciados por grupos hegemónicos; estos esfuerzos constituyen el teatro marginal, como ha sido atinadamente calificado por Juan Villegas (Ideologia y discurso 143-157). Al aplicar algunas de las proposiciones de este crítico sobre la revaluación del teatro centrada en el público destinatario y en el proceso de producción dentro de un macrosistema teatral, encontramos que durante los años sesenta y setenta hubo una inversión del discurso teatral. Por un lado, los temas anteriormente marginados pasaron a ser preponderantes, mientras que el teatro centrado temáticamente en la interioridad del personaje llegó a ser marginado; por otro lado, sucedió una inversión de los destinatarios, ya que los públicos que habían sido heredados por la década de los cincuenta disminuyeron en importancia y número, por su apego a estéticas tradicionales y su preferencia por obras extranjeras; mientras tanto se creaba un público vigoroso y joven con intereses revolucionarios, tanto en lo social como en lo estético teatral.

\section{ANÁLISIS DE LA EVOLUCIÓN DRAMÁTICA}

Un análisis de las obras más significativas del período estudiado arroja luz sobre la evolución ocurrida en el teatro hispanoamericano. Para este escrutinio se utilizó un modelo de evolución que permite hacer una comparación de las siguientes tres variables: 
1) El Género/Estilo (G): Géneros: tragedia, comedia, tragicomedia, sátira, farsa, pieza, melodrama, sainete, etc.

2) La Estructura $(E)$ : Equilibrio y coherencia de los elementos dramáticos; reglas textuales que gobiernan la integración semántica teatral.

3) El Tema (T): Objeto del discurso teatral y sus constreñimientos éticos, ideológicos y epistemológicos.

Este modelo puede ser expresado por una ecuación de funcionalidad matemática $(f)$ para los tres factores o variables independientes:

\section{Evolución dramática $=f[\mathrm{D} G, \mathrm{D} E, \mathrm{D} T]^{3}$}

en donde D (Delta) significa el cambio en cada una de las variables.

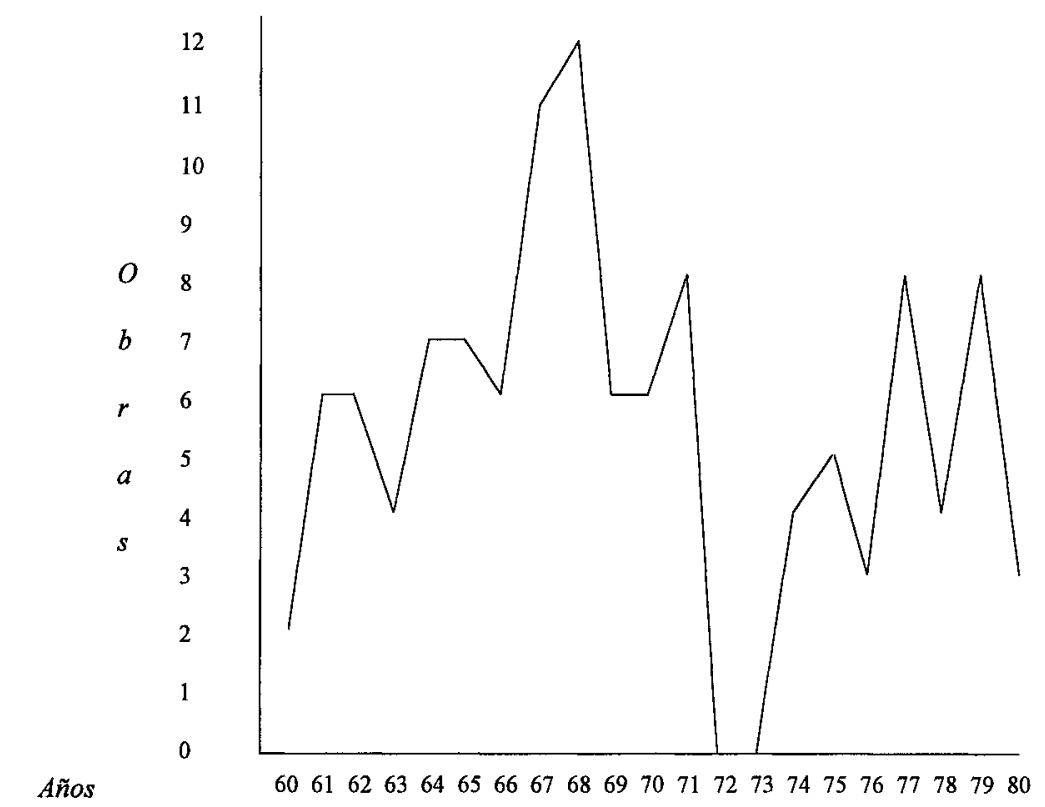

\footnotetext{
${ }^{3}$ Este modelo de Evolución dramática fue desarrollado por el autor de este artículo y primeramente utilizado en G. Schmidhuber, El teatro mexicano en cierne 1922-1938. Una obra puede presentar variantes en cada factor con respecto a otra obra anterior. Por ejemplo, un adelanto en el estilo, al aparecer elementos fársicos en un género predominantemente melodramático, mientras que la estructura dramática y el tema han permanecido inalterados, se expresaría de la siguiente manera:

Evolución dramática $=f\left[\mathrm{DG}_{2}, \mathrm{DE}_{1}, \mathrm{DT}_{1}\right]$

Este cambio representa una evolución de la obra en comparación con las tres variables anteriores. Cada nivel alcanzado se califica de "estadio de evolución," expresión que significa fase o periodo relativamente corto, según el Diccionario de la Real Academia Española. Así cuando las tres variables dramáticas han experimentado un desarrollo, el estadio de evolución se expresa:
}

Evolución dramática $=f\left[\mathrm{DG}_{2}, \mathrm{DE}_{2}, \mathrm{DT}_{2}\right]$ 
Para efectuar este análisis se seleccionaron aquellas obras que han sido consideradas significativas de la década de los sesenta (65 piezas) y de los setenta (46 piezas), ${ }^{4}$ tratando de abarcar todos los países hispanoamericanos, incluyendo a Puerto Rico y la Cuba insular y continental, para hacer con ellas un análisis comparativo de las tres variables anteriormente descritas (ver Apéndice). La incidencia de piezas representativas por años es graficada a continuación:

\section{INCIDENCIA DE OBRAS REPRESENTATIVAS 1960-1980}

Aunque el análisis está fundamentado en textos dramáticos y no en producciones, los resultados incorporan todas las tendencias estéticas, aún algunas piezas de creación colectiva. Se constató que el teatro hispanoamericano alcanzó dos estadios de evolución en el periodo estudiado, aunque en algunos casos las variables regresaron a etapas anteriores debido a un proceso de involución. La mayor proporción de estas piezas pertenece a los años 1964 a 1971, siendo 1967 el año más abundante en obras. A principios de los años setenta se registra un decrecimiento en el número de piezas que este estudio propone como significativas hasta alcanzar cero en 1973; a partir de 1975, el número crece pero sin alcanzar la alta incidencia registrada en la década anterior. En resumen, se identificaron dos etapas: la primera centrada al final de los años sesenta, la segunda se inicia al final de los años setenta, alcanzó su mayor crecimiento durante los años ochenta, y continuó vigente en la última etapa del siglo XX.

Con la utilización de la fórmula de Evolución teatral se apuntan varios cambios sucedidos durante estas dos décadas. Partimos de un estadio al inicio de los años sesenta:

$$
\text { Evolución dramática } \mathrm{X}_{1}=f\left[\mathrm{DG}_{1}, \mathrm{DE}_{1} \mathrm{DT}_{1}\right]
$$

en donde el género es realista, la estructura es preferentemente lineal y el tema es lo social (la convivencia humana en sociedad). Las siguientes piezas son representativas de este estadio: Medea en el espejo (Triana), Soledad para cuatro (Halac), El robo del cochino (Estorino), Pánfila la curandera (Teatro de la Esperanza), Milagro del mercado viejo (Dragún), Nuestro fin de semana (Cossa), etc. Esta tendencia alcanzó su clímax en 1967 con las siguientes variantes:

$$
\text { Evolución dramática } \mathrm{X}_{2}=f\left[\mathrm{DG}_{1}, \mathrm{DE}_{1}, \mathrm{DT}_{2}\right]
$$

Este estadio de evolución muestra un cambio temático al incorporar lo político (la lucha por el poder), con obras como Pueblo rechazado (Leñero), Nos tomamos la universidad (Vodanovic), Tres marias y una rosa (Benavente en creación colectiva, La revolución (Chocrón), Pedro y el capitán (Benedetti), La agonía del difunto (Navajas), Bill (Berman).

${ }^{4}$ Las obras utilizadas en el presente estudio fueron seleccionadas en forma comparativa en diversas fuentes, entre las que sobresalen Dauster, Historia del teatro hispanoamericano; Perales, Teatro hispanoamericano contemporáneo 1967-1987; y Woodyard, The Cambridge Guide to World Theatre. 
Por otro lado, al inicio de los años 80 aparecen obras con variables totalmente diferentes, según lo expresa la formulación siguiente:

$$
\text { Evolución dramática } \mathrm{Y}_{1}=f\left[\mathrm{DG}_{1}, \mathrm{DE}_{1}, \mathrm{DT}_{1}\right]
$$

con las siguientes variables: Género fársico sin temporalidad ni espacialidad reales, la estructura es compleja, y con temas que tratan de la relación de la vida interior del individuo o de las relaciones de la pareja, como en El cepillo de dientes (Díaz), La noche de los asesinos (Triana), Dos viejos pánicos (Piñera), Flores de papel (Wolff), etc. A través de estas dos décadas aparecen piezas con variables relacionadas, aunque con estructuras diversas y con evolución de género, ya que habiendo partido de la farsa absurda, se alcanzó la farsa para hacer pensar centrada en las relaciones del individuo con su sociedad:

$$
\text { Evolución dramática } \mathrm{Y}_{1}=f\left[\mathrm{DG}_{2}, \mathrm{DE}_{2}, \mathrm{DT}_{2}\right]
$$

Esta tendencia final es ejemplificada por Los siameses (Gambaro), La fiaca (Telesnik), El gran giro (Gómez Sánchez), Marathon (Monti), La misadel esclavo(Brito), etc. Concluimos que durante estas dos décadas hubo dos corrientes teatrales simultáneas: una socio-política realista " $X$ " y otra abstracta-individual "Y"; la primera tuvo su clímax al final de los años sesenta, y la segunda permaneció imperante durante el período total y pasó a ser la corriente más influyente en los años ochenta y noventa. Cuando en las dos décadas siguientes la corriente " $\mathrm{X}$ " perdió vigencia, se escribieron piezas realistas con estructura y estética similar a las pertenecientes a la década de los cincuenta, ambas teniendo el sainete como género dramático, como sucede con Rosa de dos aromas de Carballido. Este fenómeno puede ser calificado de involución.

\section{EL POSMODERNISMO Y EL TEATRO HISPANOAMERICANO}

¿Ha entrado el teatro hispanoamericano en la posmodernidad? Durante los mismos años cubiertos en el presente artículo, aparecieron numerosos ensayos anunciando mundialmente el advenimiento de una nueva etapa en el desarrollo de la humanidad: la posmodernidad. El teatro posmoderno es situado a principio de los sesenta (Connor, Postmodernist Culture 134). Los augurios proféticos de la crítica han apuntado el hecho de que las artes pictóricas y las literarias han entrado gloriosas a la posmodernidad. Por eso hoy, más que nunca, es menester analizar las posibilidades del teatro de entrar, permanecer y propasar la posmodernidad.

El teatro ejemplifica excelentemente la tensión entre el producto y el proceso, lo que es una de las condiciones de lo artístico según los pensadores de la posmodernidad, ya que el texto escrito ha dado lugar a una serie de textos intermedios hasta llegar al texto recibido por cada integrante del público en un día específico de función; así que el proceso creativo y el receptivo son fragmentarios. A esto hay que sumar que no hay forma cultural que logre unir mejor la alta cultura y la baja cultura que el teatro, ya que ni el drama clásico escapa a las circunstancias de la sociedad que lo presenta. En otros sentidos, la forma teatral reúne varios de los aspectos que los pensadores posmodernistas han propuesto como característicos de la epifanía de esta época: el desprecio de una forma esencial al no considerarla ni arte 
ni literatura; la dispersión de la identidad del trabajo de arte, con la desvalorización del texto y la creación colectiva; y la inmersión en lo social y lo político (Connor, Postmodernist Culture 133). En las dos décadas analizadas, el teatro hispanoamericano alcanzó varios logros que pueden calificarse de posmodernistas: la creación y el montaje colectivos, la recuperación de la cultura popular y la importancia de lo político: en este renglón se destacó Augusto Boal, teórico y práctico de un teatro del pueblo y para el pueblo.

A pesar de su identificación posmodernista, la presencia de lo social y lo político sobrepasó en algunos casos los límites del fenómeno teatral, con el olvido del deslinde esencial que separa el teatro de otros medios de comunicación. Su efectividad como agente comunicante es inmenso, por lo que sus mismas cualidades se convirtieron en deficiencias, ya que esta característica ha sido altamente abusada en el siglo XX. Lo político y lo teatral se confundieron en Hispanoamérica. No hay duda de que el teatro sirvió de tribuna política y qué bueno que lo hiciera, pero el mérito de algunas de estas piezas no estuvo en cambiar la conciencia del público, sino en permitirle la emoción de compartir una ideología. En este caso el teatro político es una celebración imprescindible para muchos pueblos en momentos de imperiosa unidad, pero que irremediablemente se ve sujeto a los cambios políticos y al envejecimiento con el paso del tiempo.

Por otro lado, es significativo comprobar que hasta algunas artes, como la pintura y la escultura, se han teatralizado porque algunas obras de arte parecen saber que son admiradas, como lo afirma Fried ("Art and Objecthood" 142), quien ha querido restaurar el arte en sí mismo, mediante su desteatralización. La teatralidad de las artes plásticas hispanoamericanas es intensa: el muralismo mexicano de Diego Rivera, José Clemente Orozco y Alfaro Siqueiros pintó a seres que se sabían observados y que como actores representaban con desenfado su papel. En el período cubierto por el presente estudio, el arte expresionista presenta figuras que no pertenecen al mundo de la realidad, sino a un nuevo cosmos desde el que nos miran irónicamente con una óptica teatral, como sucede con el colombiano Fernando Botero y los mexicanos Rafael Colonel y Marcos Huerta. Por otro lado, la televisión y el cine sufren hoy la invasión del teatro: la vida es reconstruida con una serie de actuaciones, por ejemplo en la noticias de televisión, ya que se utilizan técnicas de actuación para llevar a cabo hasta una entrevista. Por otro lado, el teatro ha ido imperando en la creación de estudios (sets) cinematográficos en espacios cerrados con control lumínico y con diseños no realistas. ¡Y qué importante ha sido el teatro para el rock; acaso tanto como para la política latinoamericana!

Otro factor trascendente fue la invasión de la fotografía estática y móvil en el teatro. El realismo de décadas anteriores generó el superrealismo en un intento de intensificar de la cualidad escénica de ser espejo de la realidad. El teatro realista de cuarta pared había sido el resultado del desarrollo de la fotografía y de la novela realista del siglo XIX: sin embargo el teatro, en su misma esencia, no es realista; siempre necesita que haya una convención o un pacto tácito para que el público acepte como real algo que es en esencia simulado. No hay competencia posible entre el realismo cinematográfico y el realismo teatral: nunca el teatro superará al realismo cinematográfico, como nunca el cine hará un buen Tenorio. El mérito de algunas piezas hiperrealistas fue el de acercarse al teatro ontológico. Paralelamente, la competencia entre el testimonio televisivo y el testimonio teatral siempre es favorecedora del primero. No hay mejor testimonio de la guerrilla latinoamericana o de un golpe de estado que los documentales originales de El Salvador o Nicaragua, y es imposible que una pieza 
teatral logre ese impacto. Parecería que nunca acabaremos de definir qué es teatro y qué no lo es. Por todas estas razones es imprescindible imaginar la trascendencia de un teatro liberado de su bagaje no teatral.

Durante las dos décadas analizadas en este estudio, el tema central de discusión de los teatristas latinoamericanos fue la vitalidad y la especificidad de lo teatral. La vitalidad del fenómeno teatral pudo comprobarse por su invasión a espacios escénicos no tradicionales que permitieron representaciones callejeras y de plaza que socializaron el discurso teatral. En mucho, Latinoamérica ha atendido la invitación de Artaud de regresar a lo "popular," al teatro primitivo que es percibido y experimentado directamente por la mente, sin las distorsiones del lenguaje y las limitaciones del logocentrismo (Segundo manifiesto del teatro de la crueldad 82), pero este visionario no buscaba la antitesis de la oralidad teatral, sino un teatro ritual que descubriera lo metafísico.

¿Existirán los géneros tradicionales en esta síntesis posmoderna? Por el momento es difícil saberlo, pero la farsa y el metadrama, tan en boga en Latinoamérica, apuntan al siglo $\mathrm{XXI}$, mientras que el teatro realista de cuarta pared parece quedar relegado en la modernidad, no sólo en Hispanoamérica, sino también en el resto del mundo. Indudablemente el siglo XXha adelantado grandemente el género fársico y el tragicómico; también ha experimentado con la metateatralidad, no con el concepto propuesto por Lionel Abel (Metatheatre 60-61), sino con la amplitud de posibilidades identificadas por algunos comentaristas posteriores, especialmente por Richard Hornby (Drama, Metadrama 31), es decir, con la creación de una dimensión teatral que ya no comparte naturaleza con nuestro cosmos humano, ni es regido por sus leyes. Estos entes teatrales que han sido creados por el teatro expresionista alemán -Brecht-y principalmente por el teatro del absurdo: Ionesco, Beckett, Genet, etc., son la aportación máxima del teatro del siglo XX: entes teatrales que aprendieron a vivir en el circo y el mercado, y que conocen del rito y disfrutan la ironía. También en Latinoamérica lo metadramático existe, fue creado pioneramente por algunos dramaturgos de la generación de 1924, como Rodolfo Usigli y Roberto Arlt; más tarde le siguieron Jorge Díaz, Griselda Gambaro, Elena Garro, Egon Wolff y, años más tarde, Matías Montes Huidobro, Roberto Ramos Perea y tantos otros valiosos metadramaturgos que no recrean la vida en la escena con seres verosímilmente humanos, sino con entes metadramáticos que no pueden escaparse de su cosmos escénico. Estas piezas pertenecen a un nuevo género dramático que está naciendo en Latinoamérica, la metafarsa, que es el resultado de la corriente dramática con tipología " $Y$ " que fue mencionada anteriormente. El teatro hispanoamericano que anteriormente había sido dominado por la escala de valores y por la ética ahora inicia su acercamiento hacia lo ontológico.

Otro elemento teatral que apunta hacia la posmodernidad y que es compartido con la literatura es la autorreferencialidad del proceso creativo; Linda Hutcheon lo ha calificado de narcisismo (Narcissistic Narrative). Por la autorreferencialidad la ficción se percibe como tal, mostrando a su vez el proceso de creación. El metadrama es una forma paralela de la autoconsciencia de la ficción dramática, no por la forma de "teatro dentro del teatro," sino porque los personajes de estos metadramas son entes teatrales con existencia per se que siguen existiendo aun cuando la obra parece terminada. Hay numerosos ejemplos de piezas hispanoamericanas que presentan el proceso creativo de crear una pieza, por ejemplo Los viejos de Usigli, Exilio de Montes Huidobro y Obituario de Schmidhuber. 
Otra de las características del posmodernismo es la destrucción de las barreras convencionales de los géneros y de los subgéneros, así como la importancia creciente de la ironía como perspectiva ubicua. Lo teatral ha salido del escenario "a la italiana" para invadir con sus presentaciones las plazas y los espacios abiertos; asimismo ha recibido influencias del music-hall, del circo, de las artes de espectáculo. El teatro hispanoamericano ha incorporado un abundante número de estos elementos: el corrido mexicano ha influido en la estructura dramática, así como lo han hecho otros tipos de música; la utilización en el teatro de la danza autóctona; el mercado como espacio teatral; las representaciones populares de índole religiosa, etc.

La desarmonía entre dramaturgos, director y actores (y críticos) es un síntoma más de la importancia del teatro, no como obra de teatro en sí misma, sino como trabajo-enprogreso. Es un conflicto posmodernista en un ring escénico. Por eso Bernard Dort ha invitado a la emancipación de la actuación, no ya del texto dramático como lo hizo Artaud, sino de la dictadura del director (The Liberated Performance 142). Los conflictos generados por las dictaduras teatrales han sido procesos vivificadores y purificadores del teatro hispanoamericano; sin embargo, hay que recordar la definición de Roland Barthes del teatro como densidad de signos en cooperación (Literature and Signification 261). Esta definición invita a pensar que, en el futuro, el teatro alcanzará un desarrollo mayúsculo, especialmente porque se ha ido desembarazando de la carga cultural no teatral que le había dejado el pasado; porque ha roto los grilletes de la estilistica teatral fundamentada en la verosimilitud realista. Los géneros cambiarán, la tragedia se ha ido transubstanciando en tragicomedia y en farsa; la verosimilitud ha dado paso a la metateatralidad; la visión ejemplar se ha trastrocado en ironía y polisemia; la estructura teatral anteriormente fundamentada en la causa/efecto o en la forma cerrada, ha dado paso a formas teatrales abiertas. El teatro del futuro no seráni únicamente oral, ni tampoco simplemente visual, sino que será ontológico; es decir, se orientará hacia la creación de un cosmos dramático con la creación de entes teatrales que no pretenden ser humanos, como sucede en el teatro de la verosimilitud. Algunas de las obras hispanoamericanas escritas al final de los ochenta presentan simultáneamente características dialógicas y visuales, como las de Marco Antonio de la Parra (La secreta obscenidad de cada dia) y Roberto Ramos Perea (Mistiblu).

Acaso la visión más clara del teatro en la posmodernidad es la de Herbert Blau, en su ensayo "Universals of Performance," al apuntar que lo que caracteriza al teatro contemporáneo es el deseo simultáneo de negar la teatralidad y la irremediable necesidad de volver a la teatralidad. El no querer ser teatro y tener que serlo. Para Blau la característica de inmediatez del teatro es subvertida por las convenciones de su escenificación. Así que por un lado existe la fijación del texto, las dictaduras del director y el dramaturgo, y por otro lado el proceso escénico con su libertad y su valiosa contingencia. El teatro hispanoamericano sufre este dilema de una manera intensa; por un lado ha creado un proceso creativo diferente al centrado en la hegemonía textual, intentado alcanzar lo inmediato y lo contingente, y por otro lado ha creado experiencias teatrales permanentes de indiscutible valor. La crítica más severa que se puede hacer al teatro hispanoamericano en las dos décadas analizadas es la improvisación y el poco tiempo de maduración creativa; esto es debido a las condiciones cambiantes del medio ambiente y a la parquedad de recursos, factores que indudablemente afectarán a la representatividad futura de estas piezas. La preferencia por la obra breve y la falta de reelaboración hacen que muchas de estas piezas sean únicamente montables en 
su momento de creación. Así mismo, la pérdida de balance entre lo particular y lo universal ha hecho que el discurso teatral no pase las fronteras latinoamericanas. Es significativo comprobar el reducido número de piezas hispanoamericanas que han sido montadas fuera del país de origen. Un estudio reciente ofrece el dato de obras producidas en Alemania durante la década de los ochenta: de las 210 piezas de dramaturgos hispanos, únicamente 74 fueron hispanoamericanas, es decir, el 30\% (se incluyen obras de las décadas de este estudio; Jorge Díaz fue el más montado) mientras que el resto pertenece al teatro peninsular (Soler i Marcet 34). A pesar de que en los Estados Unidos existen numerosos hispanos, muy pocas piezas hispanoamericanas llegan a subir a estos escenarios.

\section{Desiderata}

El primer ensayo que apuntó el desenvolvimiento de la modernidad hacia otra etapa posterior fue "The Dismemberment of Orpheus: Towards a Postmodern Literature" (1971), de Ihab Hassan. Orfeo fue un dios griego que perfeccionó la lira dándole dos cuerdas más; su leyenda cuenta que fue muerto por las mujeres de Tracia para apagar las iras de Afrodita, pero que su cabeza aún después de desprendida seguía cantando. Hassan propone este mito para ejemplificar el desmembramiento de la literatura a partir de la primera década del siglo XX, y la permanencia de su canto como "literatura del silencio," con una lira sin cuerdas (64). Este silencio es entendido por Hassan como rechazo y subversión, y como repudio de las formas tradicionales. ¿Por qué no imaginar que este episodio de la mitología griega también ejemplifica la victimización del teatro? No en balde la figura de Orfeo ha sido comparada con la de Dioniso porque ambos nacieron en Tracia, y en razón de que la historia de la desmembración de Orfeo tiene su paralelo en la desmembración del Dioniso Zagreo despedazado por los Titanes. Los órficos se apoderaron del mito de Dioniso y lo propusieron como centro de su culto; así que pensar que la cabeza de Orfeo representa también al teatro descoyuntado, no es falso parangón. El teatro moderno en vías de posmodernizarse está indudablemente desmembrado. Mientras la cabeza simboliza el texto, el cuerpo bien pudiera representar la escenificación, pero a pesar de que la muerte amenace al teatro, éste será eterno como el mismo Dioniso; que murió y resucitó en el segundo Dioniso. El teatro hispanoamericano no alcanzó la importancia que la novela y la poesía lograron en la segunda mitad del siglo XX, pero algunos de sus logros parecen augurar en las generaciones futuras un auge mayor a nivel continental.

\section{LA RUEDA DE DIONISOS}

¿Qué puede esperar el teatro mundial con tres mil quinientos años de historia o, según otros conteos que parten del inicio del rito comunitario prehelénico, con sus cinco mil años? Yo creo que la historia del teatro ha recorrido un ciclo que he calificado de La Rueda de Dioniso. Primero se inició con un proceso gestador que partió de la experiencia activa del rito, luego pasó por la experiencia concreta del afecto, posteriormente alcanzó la observación de lo escénico, para al final llegar a una conceptualización abstracta con el teatro del absurdo y con los llamados metadramas, que crean un mundo teatral valedero por sí mismo. Estos cuatro pasos que ha recorrido el teatro a través de los siglos presentan cuatro fases del proceso cognoscitivo: hacer, sentir, observar y pensar. En los orígenes teatrales del 
ditirambo dionisíaco, el público actuaba un rito en el que Dioniso se convertía en el único receptor y los actores eran los cuasi-sacerdotes. Posteriormente, cuando el público dejó de actuar, preponderó el sentir con el proceso afectivo que culminaba en la catarsis en unas ocasiones y, en otras, en sólo la empatía. Más adelante el público se convirtió en simple observador del espectáculo, para llegar al final de esta Rueda de Dioniso, al pensar. El teatro hispanoamericano se inició con el teatro ritual protoamericano, por desgracia hoy perdido, luego se adentró en un teatro visual y afectivo durante los tres siglos de la colonia. El teatro hispanoamericano como hoy lo entendemos nació en la primera mitad del siglo XX, intentando un balance entre lo emocional y lo intelectual, con dramaturgos pioneros como Usigli y Arlt, para más tarde intensificar los intereses visuales con un teatro realista que aún predominó en las dos décadas aquí estudiadas. A partir de las puestas de los últimos años, se ha intentado recuperar el rito, como en las puestas del grupo peruano Yuyachkani y en la dramaturgia de Enrique Buenaventura. La corriente con tipología. "Y", según se identifica en el presente estudio, inicia una tendencia de teatro de ideas que intenta balancear las cuatro vías cognoscitivas de la rueda de Dioniso.

Algunos estudiosos de las ciencias del conocimiento, como David A. Kolb, han diferenciado cuatro clases diferentes de capacidades de aprendizaje: capacidad de experiencia activa - que yo identifico con el rito-; capacidad de experimentación concreta -que yo apunto como la utilización del sentimiento en el teatro-; capacidad de observación reflexiva - que yo identifico con el teatro visual-; y capacidad de conceptualización abstracta - similar al teatro de ideas. Hasta el siglo XX, el teatro ha recorrido una primera vuelta a la rueda de Dioniso, dando al público la oportunidad de experimentar las cuatro capacidades del aprendizaje: hacer, sentir, observar y pensar. Algo que identifica al teatro hispanoamericano de última hora es su deseo de ser rito, afecto, sensación y pensamiento. Con el teatro de la crueldad, Artaud apunta la necesidad de que el teatro regresara al rito. La crítica ha entendido las consideraciones de Artaud como un regreso a los orígenes del teatro; pero quiero proponer otra interpretación, como una invitación para iniciar un segundo círculo en la rueda (o espiral) de Dioniso. Artaud no estaba equivocado; nosotros fuimos los equivocados al entenderlo como un regreso a los orígenes dionisíacos (y órficos) del teatro; la suya es una invitación a proseguir por los caminos de la posmodernidad con la mente abierta, para desmembrar el teatro e integrarlo nuevamente ahora que la rueda de Dioniso inicia su segunda vuelta.

APÉNDICE

Obras de teatro seleccionadas para este estudio

1960

Medea en el espejo, José Triana, Cuba.

1961

El robo del cochino, Abelardo Estorino, Cuba.

El cepillo de dientes, Jorge Díaz, Chile.

Lo que dejó la tempestad, César Rengifo, Venezuela.

Soledad para cuatro, Ricardo Halac, Argentina.

Versos de ciego, Luis Alberto Heiremans, Chile. 


\section{2}

El abanderado, Luis Alberto Heiremans, Chile.

La mentira, José de Jesús Martínez, Panamá.

El luto robado, Alberto Cañas, Costa Rica.

Los invasores, Egon Wolff, Chile.

El espantapájaros, Hugo Carrillo, Guatemala.

\section{3}

Y nos dijeron que éramos inmortales, Osvaldo Dragún, Argentina.

Pánfila la curandera, Teatro de la Esperanza, creación colectiva, chicana.

La crónica y el suceso, Julio Matas, Cuba.

\section{4}

La mazorca, Enrique Solari Swayne, Perú.

Milagro en el mercado viejo, Osvaldo Dragún, Argentina.

La casa vieja, Abelardo Estorino, Cuba.

Nuestro fin de semana, Roberto Cossa, Argentina.

Cóctel de Don Nadie, Francisco Arribí, Puerto Rico.

La quema de Judas, Román Chalbaud, Venezuela.

\section{5}

Procesados del 70, Alcibíades González del Valle, Paraguay.

De gatos y lunas, Beatriz Seibel, Argentina.

Yo también hablo de la rosa, Emilio Carballido, México.

Lisístrata odia la política, Franklin Domínguez, República Dominicana.

Las dos caras del patroncito, Luis Valdez, chicana.

La noche de los asesinos, José Triana, Cuba.

1966

Asia y el lejano oriente, Isaac Chocrón, Venezuela.

Fulgor y muerte de Joaquín Murrieta, Pablo Neruda, Chile.

La niña en la palomera, Fernando Cuadra, Chile.

Topografia de un desnudo, Jorge Díaz, Chile.

La huelga, Grégor Díaz, Perú.

\section{7}

La fiaca, Ricardo Talesnic, Argentina.

Felipe Ángeles, Elena Garro, México.

Los siameses, Griselda Gambaro, Argentina.

El asesinato de Malcolm $X$, Hiber Conteris, Uruguay.

La peste negra, Sergio Suárez Figueroa, Bolivia.

El hombre del sombrero de paja, Sergio Suárez Figueroa, Bolivia.

El patio de la Tocaza, Carlos Maggi, Uruguay.

Infierno negro, Demetrio Aguilera Malta, Ecuador.

Los caballos, Mauricio Rosencof, Uruguay. 
La lanza capitana, Raúl Botelho Gosálvez, Bolivia.

Oficio de hombres, Andrés Morris, Honduras.

\section{8}

Antigona, Luis Rafael Sánchez, Puerto Rico.

Los unos 'vs' los otros, José Martínez Queirolo, Ecuador.

Dos viejos pánicos, Virgilio Piñera, Cuba.

Quetzalcóatl, Luisa Josefina Hernández, México.

La muchacha de Hamburgo, Gastón Suárez, Bolivia.

La colina, Daniel Gallegos, Costa Rica.

Los papeles del infierno, Enrique Buenaventura.

Los viejos baúles empolvados que nuestros padres nos prohibieron abrir, Carlos José Reyes, Colombia.

El amasijo, Osvaldo Dragún, Argentina.

El campo, Griselda Gambaro, Argentina.

Delito, condena y ejecución de una gallina, Manuel José Arce, Guatemala.

Pueblo rechazado, Vicente Leñero, México.

1969

Pirámide 169, Máximo Avilés Blonda, República Dominicana.

El cruce sobre el Niágara, Alonso Alegría, Perú.

Jugando a la gallina, Roberto Armijo, El Salvador.

Ayax Telemonio, Enrique Solari Swayne, Perú.

Tres generaciones, Raúl Salmón, Bolivia.

Nos tomamos la universidad, Sergio Vodanovic, Chile.

\section{0}

Tus alas, Ariel, Ligia Bernal, Guatemala.

Un niño azul para esa sombra, René Marqués, Puerto Rico.

Muerte, S.A., Demetrio Aguilera Malta, Ecuador.

Barbarroja, Rodolfo Santana, Venezuela.

La trilogía del matrimonio, Rolando Steiner, Nicaragua.

Flores de papel, Egon Wolff, Chile.

1971

Los viejos, Rodolfo Usigli, México.

Un tal Manuel Rodríguez, Sergio Arrau, Chile.

La revolución, Isaac Chocrón, Venezuela.

Texas en carretilla, Diana Raznovich, Argentina.

La sal de los muertos, Matías Montes Huidobro.

Las fisgonas de Paso Ancho, Samuel Rovinski, Costa Rica.

Cuidado que viene de España, Renato Crespo, Bolivia.

Aquel 1811, José Luis Appleyard, Paraguay. 
1972

Los pájaros se van con la muerte, Edilio Peña, Venezuela.

Juan Palmieri, Antonio Larreta, Uruguay.

Inmaculada, Héctor Azar, México.

$1974(1973=0)$

Ceremonias, Julio Ortega, Perú.

Tupac Amaru, David Viñas, Argentina.

I took Panamá, Luis Alberto García, Colombia.

Se administra justicia, Sara Joffré, Perú.

1975

Pequeños animales abatidos, Alejandro Sieveking, Chile.

Guadalupe años cincuenta, Santiago García, Colombia.

Mata a tu prójimo como a tí mismo, Jorge Díaz, Chile.

El señor Galíndez, Eduardo Pavlovsky, Argentina.

Bernabé, Luis Valdez, Estados Unidos (chicana).

1976

Telarañas, Eduardo Pavlovsky, Argentina.

El sol subterráneo, Jairo Aníbal Niño, Colombia.

Acto cultural, Ignacio Cabrujas, Venezuela.

1977

Visita, Ricardo Muti, Argentina.

Nuevas aventuras de Simón Bolivar contadas por un testigo presencial, Leonardo Kosta,

Ecuador.

La agonia del difunto, Estaban Navajas, Colombia.

El gran giro, Luis Gómez Sánchez, Perú.

La nona, Roberto Cossa, Argentina.

El juego, Mariela Romero, Venezuela.

¿Cuántos años tiene un día?, Sergio Vodanovic, Chile.

Los payasos de la esperanza, Taller de Investigación Teatral, Chile.

1978

Testimonio sobre las muertes de Sabina, Juan Radrigán, Chile.

Convivencia, Oscar Vale, Argentina.

El destete, Ricardo Halac, Argentina.

Lo crudo, lo cocido y lo podrido, Marco Antonio de la Parra, Chile.

1979

Tres marias y una rosa, David Benavente (Taller de Investigación Teatral), Chile.

¿Qué sucedió en Pasos?, César Vega Herrera, Perú.

Una noche con el señor Magnus e hijos, Ricardo Monti, Argentina. 
Atlántida, Oscar Villegas, México.

Historia de una bala de plata, Enrique Buenaventura, Colombia.

Pedro y el capitán, Mario Benedetti, Uruguay.

Bill, Sabina Berman, México.

María Picana, Raúl Leis, Panamá.

1980

Marathon, Ricando Monti, Argentina

Los herederos de Segismundo, Guillermo Schmidhuber, México.

La misa del esclavo, Luis Brito, Venezuela.

Bibliografía

Abel, Lionel. Metatheatre. A New View of Dramatic Form. New York: Hill and Wang, 1963.

Arrom, José Juan. Esquema generacional de las letras hispanoamericanas. Bogotá: Instituto Caro y Cuervo, 1977.

Artaud, Antonin. "The Theatre of Cruelty: Second Manifesto". The Theatre and Its Double. London: Calder and Boyars, 1970.

Barthes, Ronald. "Literature and Signification". Critical Essays. Evanston: Northwestern University Press, 1972.

Boal, Augusto. Teatro del oprimido. México: Nueva Imagen, 1980.

Bravo Elizondo, Pedro. Teatro documental latinoamericano. México: Universidad Nacional Autónoma de México, 1982.

Blau, Herbert. "Universals of Performance." The Eye of Prey: Subversions of the Postmodern. Bloomington: Indiana University Press, 1987.

Cánepa Guzmán, Mario. Historia del teatro chileno. Chile: Editorial Universidad Técnica del Estado, 1974.

Connor, Steven. Postmodernist Culture: An Introduction to Theories of the Contemporary. Oxford: Basil Blackwell, 1991.

Dauster, Frank D. Historia del teatro hispanoamericano. México: Ediciones de Andrea, 1973.

Dort, Bernard. "The Liberated Performance". Modern Drama 25.1 (1982), 62-65.

El teatro latino americano de creación colectiva. Ed. Marina García. Cuba: Casa de las Américas, 1978.

Fried, Michael. "Art and Objecthood." Minimalist Art. Ed. Geoffrey Battcock. New York: Dutton, 1968.

Jones, Willis Knapp. Behind Spanish American Footlights. Austin: Texas University Press, 1966.

Hassan, Ihab. The Dismemberment of Orpheus: Toward a Postmodern Literature. New York: Oxford University Press, 1982.

Hornby, Richard. Drama, Metadrama, and Perception. London: Bucknell University Press, 1986.

Hutcheon, Linda. Narcissistic Narrative: The Metafictional Paradox. Ontario: Wilfred Laurier University Press, 1980. 
. A Poetics of Postmodernism: History, Theory, Fiction. New York: Routledge, 1988 .

Kolb, David A. Experiental Learning: Experience as the Source of Learning and Development. Englewood Cliffs: Prentice-Hall, 1984.

- Organizational Psychology: An Experiential Approach to Organizational Behavior. Englewwod Cliffs: Prentice-Hall, 1984.

Leal, Rine. Breve historia del teatro cubano. Cuba: Editorial Letras Cubanas, 1980.

Montes Huidobro, Matías. Persona, viday máscara en el teatro cubano. Miami: Ediciones Universal, 1973.

Perales, Rosalina. Teatro hispanoamericano contemporáneo 1967-1987. México: Grupo Editorial Gaceta, 1989.

Rojo, Grínor. Muerte y resurección del teatro chileno 1973-1983. Chile: Ediciones Michay, 1985.

Rizk, Beatriz J. El nuevo teatro latinoamericano: una lectura histórica. Minneapolis: Prisma Institute, 1987.

Saz, Agustín del. Teatro hispanoamericano. Barcelona: Editorial Vergara, 1963 y 1964. Volumen 1 y 2. . Teatro social hispanoamericano. Barcelona: Editorial Labor, 1967.

Schmidhuber, Guillermo. El teatro mexicano en cierne, 1922-1938 New York: Peter Lang, 1992.

Solórzano, Carlos. Teatro latinoamericano del siglo XX. México: Editorial Pormaca, 1969.

Soler i Marcet, María-Lourdes. "Dramaturgia hispana en tablas germánicas en la década de los ochenta". Estreno 8.1 (1992), 33-36.

Suárez Radillo, Carlos Miguel. Lo social en el teatro hispanoamericano contemporáneo. Caracas: Equinoccio, 1976.

Villegas, Juan. Ideología y discurso crítico sobre el teatro de España y América Latina. Minneapolis: The Prisma Institute, 1988.

Woodyard, George. "Teatro Latinamericano". The Cambridge Guide to World Theatre. Ed. Martin Ganham. Cambridge: Cambridge University Press, 1988. 